\title{
De Llull a Estellés. Sobre els «Cant de Ramon» i «Cant de Vicent»
}

\section{Llull in Estellés. About «Cant de Ramon» and «Cant de Vicent»}

\author{
FerRan CARbó \\ Universitat de València \\ ferran.carbo@uv.es \\ Recibido: febrero de 2017. Aceptado: abril de 2017
}

\begin{abstract}
Resum: Aquest treball analitza la relació transtextual que es va produir a la fi dels anys cinquanta entre el poeta valencià Vicent Andrés Estellés i el seu predecessor Ramon Llull. L'edició el 1957 d'Obres essencials de Ramon Llull en possibilità la seua lectura i va facilitar l'evolució de la poesia d'Estellés mitjançant les connexions amb textos clàssics. L'estudi revisa com cadascun dels dos autors va escriure un Llibre de meravelles, separats tots dos per set segles, el primer escrit en prosa narrativa i el segon en poemes; i sobretot aprofundeix en un exemple d'intertextualitat: Llull havia escrit el «Cant de Ramon» i Estellés va fer el «Cant de Vicent», poemes que es caracteritzen i es contrasten
\end{abstract}

Mots clau: transtextualitat, Llull, Estellés, Llibre de meravelles, «Cant de Ramon», «Cant de Vicent»

\begin{abstract}
This paper analyzes the transtextual relation that ocurred in the late fifties between the Valencian poet and his predecessor. The 1957 edition of the book Obres essencials made possible its reading and facilitate the evolution of Estellés' poetry through connections with classical texts. The study reviews how both writers, separated by seven centuries, wrote a Llibre de meravelles, the first written in narrative prose and the second in poems; and especially it examines an example of intertextuality: as Llull wrote «Cant de Ramon», and Estellés wrote «Cant de Vicent», two poems that this paper characterizes and contrasts.
\end{abstract}

Key words: Transtextuality, Llull, Estellés, Llibre de meravelles, poems «Cant de Ramon», «Cant de Vicent» 
L'any 1957, entre el 4 i el 7 d'abril, per primera i última vegada en la seua vida, Carles Riba va visitar València, en un viatge gestionat sobretot per Joan Fuster (Carbó 2016: 67-80). En aquesta ciutat fou acompanyat, entre d'altres, pel poeta Vicent Andrés Estellés, el qual aleshores admirava la poesia de l'autor barceloní mentre llegia intensament literatura escrita en llengua catalana, tant contemporània com medieval. Estellés fins aleshores era un autor de formació en llengua castellana, des que el 1944 havia començat a publicar poemes solts en revistes literàries; tanmateix, a partir del 1953 havia descobert en els versos de Riba una poesia en llengua catalana radicalment diferent d'aquella que abans havia llegit en els versos de Teodor Llorente, el patriarca de la poesia valenciana de la fi del segle XIX i l'inici del Xx, qui, a més a més, fou el fundador del rotatiu Las Provincias, on treballava com a periodista el poeta de Burjassot. Si la poesia catalana coetània fou essencial per a la incorporació del català com la seua llengua literària i per a la seua primera evolució poètica, també ho foren els clàssics.

Aquell mateix 1957 es publicava a Barcelona un primer volum d'Obres essencials de Ramon Llull, en l'editorial Selecta (Llull 1957-1960). Aquest fou un punt d'accés a un conjunt d'obres lul-lianes per part de diferents escriptors durant la postguerra. Un entre tants, Estellés hi arribava mentre també ho feia a la poesia d'Ausiàs March. De fet, en un document mecanoscrit inèdit posterior, intitulat ben marquianament «Primer cant de mort», del Fons Estellés a l'arxiu familiar de Burjassot, que es pot datar entre els 1967 i 1968, hi ha versos com el següent: «Invoques Ramon Llull, invoques Ausiàs,/ i ningú no et contesta; temptes murs, els dies;».

Una prova clara d'aquestes presències d'escriptors clàssics són les citacions que encapçalaven la primera edició del seu poemari La clau que obri tots els panys, un llibre escrit entre els anys 1954 i 1957, que el 1958 va guanyar el premi València de la Diputació Provincial en la modalitat de poesia: aleshores aquest era el premi literari més rellevant al País Valencià. Tot i que es tenia prevista l'edició del llibre per al 1959 o el 1960, tanmateix, no es va publicar fins al 1971. És ben il-lustratiu de revisar les citacions de l'obra en la seua primera edició: la citació preliminar del conjunt és d'Ausiàs March. Si es miren les set citacions prèvies que encapçalen la primera de les tres parts del llibre, aquestes són d'Ausiàs March, Bernat de Ventadorm, Jaume March, Jaume Roig, Ramon Llull, Rosselló-Pòrcel i Vicent Ferrandis. La de Ramon Llull diu així: «Que us mostrarà a vençre vostre cor combatut». Si ens fixem en les set citacions que precedeixen la segona part, intitulada «Llibre d'exilis» (les quals es van reduir a tres citacions a partir de la segona edició), aquestes són de Jordi de Sant Jordi, Llull, Sor Isabel de Villena, Ausiàs March, Marcabrú, Ausiàs March i Roís de Corella. La de Llull diu així: «E exilats de bona amor», ben en sintonia amb l'intertítol de la part. La tercera part (retolada «Coral romput») no té citacions prèvies al conjunt però, en canvi, té tres epígrafs que precedeixen cadascun dels tres llargs poemes, els quals són d'Ausiàs March, Bernat Fenollar i Sant Vicent Ferrer. El medievalisme dominant en aquests paratextos és evident. Comptat i debatut, a banda del poeta del segle XV del senyal «Plena de seny» (Aparicio 2003), Ramon Llull és l'únic escriptor repetit. Cal tenir present que La clau que obri tots els panys és un dels principals títols de l'extensa pro- 
ducció estellesiana, i que la datació de l'acabament de la seua escriptura cal situar-la sols un any abans de l'inici de la redacció de poemes del seu futur Llibre de meravelles.

L'edició d'obres de l'escriptor mallorquí el 1957 va coincidir cronològicament amb aquest interès i quan Estellés les va llegir, segurament entre el 1957 i el 1959, com a molt tard, sens dubte es va potenciar intensament la presència de Llull en els seus textos. També va influir-hi considerablement el fet que començaren els viatges a Mallorca, on vivia el seu cunyat Marce1.lí Lorente, germà de l'esposa Isabel, un indret que esdevingué rellevant en la seua vida i fou ben present en la seua producció literària. En aquesta illa faria amistats profundes com la del poeta Josep Maria Llompart. El coneixement directe, per viatjar-hi, de Catalunya (des del 1952) i de Balears (des del 1959) va fer créixer amb la fermesa la consciència de la seua catalanitat cultural. El seu primer viatge a Mallorca l'anunciava, en vers, a «Rajoletes», el primer poema de L'inventari clement, un text datat el 1958: «Hem d'anar a Mallorca qualque dia. / Hem d'anar a Mallorca». I, en les seues memòries en prosa, recordava aquella primera estada: «Hi vaig arribar una setmana santa indecorosament plujosa. Vam anar a viure amb la família» (Andrés Estellés 2013: 219).

Fou el 1958 quan Estellés va començar i va escriure bona part dels poemes del que el 1971 editaria com a Llibre de meravelles, amb el subtítol Poemes, obra que ratificava la importància de Llull per ser autor també, set segles abans, d'un Llibre de meravelles. Fet i fet, com ha assenyalat Aparicio, «en la utilització del mateix títol lul-lià s'ha de veure la voluntat explícita i deliberada per part d'Estellés de remetre a una mateixa tradició literària que serveix de recolzament a la seua obra poètica» (Aparicio 2013: 93). En el volum d'Estellés, com a vuitè poema de la secció III de la part central, hi ha un «Cant de Vicent». Curiosament, el mallorquí a la fi del 1299 o el 1300 havia escrit un «Cant de Ramon».

Si partim de la proposta de Genette (1982: 7-17), la transtextualitat inclouria una varietat de connexions i de relacions possible entre textos. Paratextualitat, intertextualitat i fins i tot hipertextualitat i arxitextualitat són algunes de les possibilitats ben explorades pel poeta valencià, per exemple en el seu Llibre de meravelles. La intertextulitat remet a una relació de copresència d'un text en un altre. Aquesta pot ser mitjançant la citació, que respon a la reproducció exacta i explícita; el plagi o reproducció literal i no explícita; l'al·lusió o reproducció no explícita ni literal; i la referència o préstec explícit però no literal que fa l'enllaç amb l'esment, la referència del nom de l'autor o del títol de l'obra (Piégay-Gros 1996: 45-55). Tot plegat possibilita un joc de relacions intertextuals, que la lectura ha d'esbrinar, en els casos no explícits, per completar o ampliar els sentits del nou text.

Dues mostres clares d'aquest enllaç transtextual són el títol del poemari Llibre de meravelles i dins d'aquest el poema «Cant de Vicent». El seu llibre, segons l'autor de Burjassot, fou escrit entre els anys 1956 i 1958; tanmateix, segons la documentació existent al Fons Estellés, una bona part dels seus textos van ser elaborats majoritàriament al voltant dels anys 1958 i 1959, i l'obra 
es va complementar i acabar el 1968 per a la primera edició del 1971. Curiosament, en aquest poemari hi ha cinc citacions preliminars al conjunt del llibre i, a més a més, quaranta-set epígrafs que precedeixen poemes: cap d'aquests, ni les unes ni els altres, és de l'escriptor mallorquí del XIII. Això no obstant, el títol del llibre i el del poema esmentat són determinants i, a més, definitoris; així com també la segona de les citacions preliminars que és de Miquel Batllori però que diu així: «No sabem amb exactitud per què (Ramon Llull) l'anomenà Llibre de meravelles... Així es comprèn millor per què el Llibre de meravelles és una novel-la episòdica: en el seu origen fora com una guia espiritual...». La citació prové de la introducció que Batllori en féu el 1957 dins Obres essencials de Ramon Llull, i que comportà un major i millor accés i coneixement de l'autor mallorquí i del seu Llibre de meravelles. Aquesta citació en ratifica la lectura del volum lul-lià del 1957 per part d'Estellés, l'únic indret d'on llavors la podia agafar. El fet d'aparèixer, set segles després, un nou Llibre de meravelles (ara de poemari), inicialment un títol plagiat ja que és literal i no explícit, situa els lectors de l'obra d'Estellés en l'òrbita de Llull, la qual cosa la citació preliminar del pare Miquel Batllori confirma i arrodoneix amb escreix. Aquesta citació, juntament amb el subtítol de l'obra estellesiana en la seua primera edició Poemes (mot que matisa i també diferencia el títol respecte al de Llull, i que fou suprimit a partir de la segona edició no feta ja per L'Estel sinó per Edicions Tres i Quatre), però, ens fan passar, primer, de la idea del possible plagi a l'al-lusió (pel subtítol a la portada, que matisa i diferencia) i, després, al préstec (per la citació que apareix a la primera pàgina). El poeta de Burjassot no sols al-ludeix al beat mallorquí sinó que sobretot li agafa el títol com a prèstec. Qualsevol lector que conega una mica la literatura catalana en fa l'enllaç entre les dues obres i els dos autors immediatament.

Ambdues obres intitulades Llibre de meravelles, la de Llull i la d'Estellés, opten per la dispositio, per l'arquitectura, per la construcció. El poemari de meravelles estellesià combina alhora l'estructura ternària del tríptic (com els de la pintura medieval) amb l'acumulació d'episodis escenes del retaule, perquè hi ha una estructura de tres parts o cossos (dos de laterals, «Teoria i pràctica de la flor natural» $\mathrm{i}$ «Propietats de la pena», $\mathrm{i}$ un de central, que conté set seccions numerades I-VII —-sense un títol integrador-, $\mathrm{amb}$ un conjunt de quaranta-set poemes agrupats, respectivament: amb sis, vuit, deu, un, vuit, tretze i un poemes per a cadascuna de les set seccions). També el llibre de prosa medieval de Llull tenia un prefaci i un epíleg, que emmarcaven, com laterals extrems, el conjunt de les deu parts o llibres que el constituïen i estructuraven.

Quan llegim dins el poemari estellesià Llibre de meravelles el «Cant de Vicent», sense cap mena de dubte, apareix latent el «Cant de Ramon». Llavors, d'una banda, podem fer la lectura del text «Cant de Vicent» com un poema més del llibre del qual forma part o com un poema condicionat pel poema quasi homònim lul-lià. Convé matisar, però, que mentre el poema «Cant de Vicent» sí que pertany al Llibre de meravelles d'Estellés; el «Cant de Ramon», en canvi, no hi pertanyia a l'homònim de Llull, llibre que era, recordem-ho, de prosa narrativa. 
Com que hi havia un «Cant de Ramon» de Llull, escrit a l'entorn de la fi del 1299 o l'any 1300 (Riquer 1980: 224; Romeu 1983), Estellés agafa, ja el 1958, la idea de fer un «Cant de Vicent»; poc després de llegir la selecció d'Obres essencials, de Llull, del 1957, al volum I, on, a més de Llibre de meravelles del mallorquí (Llull 1957, I: 309-511); també hi havia el seu «Cant de Ramon» (Llull 1957, I: 1301-1302). Aquell 1958, l'any dels primers textos del poemari d'Estellés, es va publicar a Barcelona Poesies, de Ramon Llull, a càrrec de Josep Romeu. En la biblioteca del poeta de Burjassot no es troba, però, cap d'aquests volums (ni el preparat per Romeu ni el de Batllori et alii.), però sí, en canvi, per esmentar-ne edicions antigues, hi havia l'edició de Llibre d'amic e amat, publicada a Barcelona el 1935 per Barcino, o una Antología de Ramon Llull, editada el 1961 a Madrid per la Dirección General de Relaciones Culturales. Així doncs, l'interès lul-lià hi era ben palès.

Tot i ser els dos cants dos textos llargs, els reproduïm tot seguit. Els títols tenen el mot cant idèntic, de caràcter remàtic, i el del nom de l'autor, diferent, més aviat temàtic, com a protagonistes dels seus respectius poemes. Són, doncs, en la terminologia genettiana (1987) títols mixtos. No cal dir que el segon copia el títol del primer, però convertint el possible plagi en amagada al-lusió. En el cant antic seguim la versió que presenta Josep Romeu (1983 i 1985) basada en la de S. Galmés:

\section{CANT DE RAMON}

Són creat e ésser m'és dat

a servir Déu que fos honrat, e són caüt en mant pecat.

En ira de Déu fuy pausat;

Jhesús me venc crucificat:

volc que Déus fos per mi amat.

Matí ané querre perdó

a Déu, e pres confessió

ab dolor e contrició.

De caritat, oració,

esperansa, devoció,

Déus me fé conservació.

Lo monestir de Miramar

fiu a frares Menors donar

per sarrayns a preïcar.

Enfre la vinya e. 1 fenolar

amor me pres, fe'm Déus amar,

e.nfre sospirs e plors estar. 
Déus Payre, Fil, Déus espirat, de qui és sancta Trinitat, tracté com fossen demonstrar. Déus Fill, del cel és devalat; de una verge està nat, Déu e home, Crist appelat.

Lo món era en damnació; morí per dar salvació Jhesús, per qui·l món creat fo. Jhesús pujà-l cel sobre el tro; venrà a jutjar li mal e.l bo: no volran plors querre perdó.

Novel saber ay atrobat; pot-n. hom conèxer veritat e destruir la falsetat.

Sarrayns seran batejat, tartres, jueus e mant errat, per lo saber que Déus m’à dat.

Pres ay la crots. Tramet amors a la Dona de peccadors que d'ela m'aport gran secors. Mon cor està casa d'amors e mos huyls fontanes de plors: enfre gaug estag e dolors.

Són hom veyl, paubre, meinspreat, no ay ajuda d'home nat, e ay trop gran fait emparat. Gran res ay de lo món sercat, mant bon exempli ay donat: poc són conegut e amat.

Vuyl morir en pèlec d'amor. Per ésser gran non ay paor de mal príncep ni mal pastor. Tots jorns consir la deshonor que fan a Déu li gran senyor qui meten lo món en error. 
Prec Déus trameta missatjers

devots, sciens e vertaders, a conèxer que Déus hom és.

La Verge on Déu hom se fés e tots los sants d'ela sotmès, prec qu·en ifern no sia mès.

Laus, honor al major Senyor, al qual tramet la mi. amor que d'él reeba resplandor. No són digne de far honor a Déu: tan fort són peccador e són de libres trobador!

On que vage cuyt gran bé far, e a la fi res no.y pusc far, per què n'ay ira a pesar. Ab contrició e plorar vuyl tant a Déu mersè clamar que mos llibres voyl- exalsar.

Santedat, vida, sanitat gaug, me dó Déus e libertat, e gart-me de mal e peccat.

A Déu me són tot comanat: mal esperit ne hom irat no hagen en mi potestat.

Man Déus als cels e·ls elements, plantes e totes res vivents que no.m fassen mal ni tormens. Dó'm Déus compayons conexents, devots, leials, humils, tements, a procurar sos honraments.

Laus et honor essencie Dei et diuinis personis et dignitatibus earum. Et recordemur et amemus Jhesum Nazarenum et Mariam virginem matrem eius.

Llull va viatjar a París per presentar la seua art doctrinal a la Sorbona, on hi romangué fins al juliol del 1299. En aquest moment és quan la historiografia 
literària situa l'escriptura del seu cant (entre la fi del 1299 o el 1300). La composició d'aquest llarg poema es va poder fer quan va tornar de París, decebut pel poc que havia aconseguit amb els seus plantejaments, i quan es va assabentar de l'abandonament de Miramar, que ell amb altres havia organitzat i gestionat, com esmenta a la tercera cobla. Josep Romeu ha comentat extensament el text i ha subratllat que «no podem destriar la forma del contingut, més ben dit: la voluntat estètica de la intenció apologètica, aquí particularment tenyida d'intimisme» (Romeu 1983: 449).

El poema consta de vuitanta-quatre octosíllabs organitzats en catorze cobles o estrofes de sis versos de rima consonant monorima i aguda (rimes que es recuperen sovint en altres noves estrofes i que solen tenir un accent dominant en quarta síl-laba). Les cobles de sis versos naixen de la fusió de dues unitats oracionals, en forma de tercines, fonamentades per tant des del punt de vista sintàctic, les quals tenen una certa autonomia entre elles dins l'estrofa a què pertanyen. El text llatí reproduït, d'acompanyament final, és com un complement independent.

El cant té dues parts de contingut i actitud, perfectament equilibrades les quals abracen cadascuna set estrofes. La primera presenta un recorregut autobiogràfic per algunes dades personals, des del naixement i la seua conversió, el seu pas pel monestir de Miramar i la seua formació (sobretot les tres primeres estrofes), alguns coneixements (Trinitat, encarnació de Jesucrist, Judici Final...) i la doctrina (nou saber, la redacció de l'art) per a la seua tasca missional (les altres quatre estrofes). De sobte, a partir de l'estrofa vuitena, es presenta vell, pobre i menyspreat, com camí de la mort, amb penediment i sobretot amb el fet d'encomanar-se a Déu i la Verge. L'estratègia, per part de l'emissor, de mostrar-se com l'home feble anímicament derrotat i injustament tractat, dedicat plenament a la tasca missional, afavoreix l'adhesió del receptor. El jo poètic dubta de l'èxit i poc ressò aconseguit malgrat dedicar-s'hi tota la vida i demana a Déu no sols protecció en els darrers moments de la seua vida sinó sobretot (en dues ocasions, els tres primers versos de l'estrofa desena i els tres darrers versos de l'estrofa catorzena) que hi haja «companyons coneixents», és a dir, gent preparada i formada per tal de continuar la tasca: en el rerefons i subliminarment com aquella que podria formar-se al monestir de Miramar, en el qual Llull havia residit i, com ja s'ha assenyalat, n'organitzà el seu funcionament. Si s'abandonava o es clausurava el monestir, llavors d'on sorgiria aquesta gent preparada?

Aquest «Cant de Ramon» va motivar, com a punt de partença, el «Cant de Vicent», dos textos autobiogràfics i doctrinals. Com ja hem assenyalat, Estellés va poder llegir el cant en Obres essencials de Llull, des que el 1957 se'n publicà el primer volum, el mateix en què apareixia Llibre de meravelles. Així doncs, aquest fet ens situa en una cronologia de lectura quan elaborava els materials poètics per al seu Llibre de meravelles. El cant estellesià és el poema tretzè en l'ordenació del document mecanoscrit d'aquests materials del Fons Estellés per a la seua obra. En l'edició és el vuitè poema de la secció III de la part o cos central. Hi ha un Llibre de meravelles. Poemes perquè n'hi havia un llibre en prosa, set segles anterior; així com també hi ha un «Cant de Vicent» perquè hi hagué un «Cant de Ramon». 
El lligam i la connexió ja es produeix des del títol i sobretot pel títol. En els dos casos un cant, un poema llarg, $i$ un subjecte poemàtic (jo en el primer text $i$ $t u$ desdoblat — amb un jo complementari- en el segon) del qual es presenten aspectes personals (clarament autobiogràfics) alhora que es mostra una crisi. A més, s'exposa doctrina evangèlica i missional en el poema medieval i doctrina poètica en el contemporani. Mirem el segon text:

\section{CANT DE VICENT}

... a unes tres milles de la mar, a la banda occidental del riu Guadalaviar, sobre el qual hi ha cinc ponts...

SIR JOHN TALBOT DILLON

Pense que ha arribat l'hora del teu cant a València.

Temies el moment. Confessa-t'ho: temies.

Temies el moment del teu cant a València.

La volies cantar sense solemnitat,

sense Mediterrani, sense grecs ni llatins,

sense picapedrers i sense obra de moro.

La volies cantar d'una manera humil,

amb castedat diríem. Veies el cant: creixia.

Lentament el miraves créixer com un crepuscle.

Arribava la nit, no escrivies el cant.

Més avant, altre dia, potser quan m'haja mort.

Potser en el moment de la Resurrecció

de la Carn. Tot pot ser. Més avant, si de cas.

I el tema de València tornava, i se n' anava

entre les teues coses, entre les teues síl-labes,

aquells moments d'amor i aquells moments de pena,

tota la teua vida — si no tota la vida,

allò que tu saps de fonamental en ella-

anava per València, pels carrers de València.

Modestament diries el nom d'algun carrer,

Pelayo, Gil i Morte... Amb quina intensitat

els dius, els anomenes, els escrius! Un poc més,

i ja tindries tota València. Per a tu,

València és molt poc més. Tan íntima i calenta,

tan crescuda i dolguda, i estimada també!

Els carrers que creuava una lenta parella,

els llargs itineraris d'aquells dies sense un 
cèntim a la butxaca, algun antic café, aquella lleteria de Sant Vicent de fora...

La casa que estrenàreu en estrenar la vida definitivament, l'alegre veïnat.

El metge que buscàveu una nit a deshora, la farmàcia de guàrdia. Ah, València, València!

El naixement d'un fill, el poal ple de sang. Aquell sol matiner, les Torres dels Serrans amb aquell breu color inicial de geranis. Veus, des del menjador, per la finestra oberta, Benimaclet ací, enllà veus Alboraia, escoltes des del llit les sirenes del port.

De bon matí arribaven els lents carros de l'horta.

Els xiquets van a escola. S'escolta la campana veïna de l'església. E1 treball, el tenaç amor a les paraules que ara escrius i has dit sempre, des que et varen parir un dia a Burjassot: com mamares la llet vares mamar l'idioma, dit siga castament i amb perdó de la taula. Ah, València, València! Podria dir ben bé: $\mathrm{Ah}, \mathrm{tu}$, València meua! Perquè evoque la meua València. O evoque la València de tots, de tots els vius i els morts, de tots els valencians? Deixa-ho anar. No et poses solemne. Deixa l'èmfasi. L'èmfasi ens ha perdut freqüentment els indígenes.

Més avant escriuràs el teu cant a València.

L'epígraf remet a una descripció d'un segment del riu Túria, que va fer l'escriptor irlandès John Talbot Dillon. Aquest riu s'anomena Guadalaviar en un tram del seu naixement i quan la citació esmenta cinc ponts evoca i suggereix els ponts de la ciutat de València. L'epígraf, per tant, preludia la ciutat del cant que el seguirà. L'autor de l'epígraf fou un viatger que va escriure a la fi del segle XVIII obres de viatges per la península. Llull també era, entre altres coses, un viatger.

El cant és un seguit de cinquanta-tres alexandrins blancs (amb cesura i dos hemistiquis de sis sílllabes, per tant amb uns accents constant en la sisena $i$ en la dotzena), sense estrofes ni rima. És també un llarg poema, tot i que la formalització s'allunya de la del cant de Llull, i sintonitza plenament amb el conjunt del poemari de les meravelles estellesianes, que té com a vers dominant l'alexandrí agrupat en poemes sense organització estròfica. 
La figura del poeta es projecta amb la veu d'un jo resposable de l'enunciació $\mathrm{i}$ alhora es desdobla en un protagonista $t u$, en segona persona del singular, que és Vicent i que irromp en dues ocasions amb veu en estil directe (com un altre jo), sense marques tipogràfiques, i, per tant, aconsegueix una polifonia i interferència de veus. Així l'escriptor de Burjassot es distancia del text de Llull també per l'enunciació: ara no hi ha la confessió directa d'un jo, que representava el Ramon del títol i Ramon Llull per les dades autobiogràfiques que s'esmentaven, sinó que hi ha una reflexió suggerida des d'un to conversacional i amb un caire, de vegades, instruccional, d'un jo, quasi amagat o si més no retirat, a un $t u$ ben explícit: tot incitant-lo a l'acte d'escriure un text $\mathrm{i}$, més concretament, mitjançant una concreta concepció poètica de l'escriptura.

Aquest $t u$ protagonista, amb l'estratègia del desdoblament, es caracteritza per tenir molts aspectes autobiogràfics d'Estellés: Burjassot («et varen parir un dia a Burjassot», diu el v. 44), indrets de València (des de la lleteria del carrer sant Vicent fins a l'àtic on es va establir a viure al carrer Misser Marcó, 17, porta 29, des d'on es veien pobles propers que s'hi esmenten, com Benimaclet o Alboraia), la nit del naixement d'un fill (la seua primera filla Isabel va nàixer el novembre del 1955), l'idioma...

El tema de l'escriptura del poema - i l'objectiu que cal assolir- queda establert al primer vers, el qual enceta una estructura emmarcada que es recupera i completa a la fi, en els tres darrers versos (vv. 51-53), que, a més, integren el jo i el tu (v. 52, amb el pronom ens que indica la primera persona del plural). Des del primer vers es fixa com a objectiu escriure un cant però no sobre Vicent sinó, especialment, sobre València, l'indret on viu: «escriure el teu cant a València». S'hi estableix, doncs, una dualitat amb el cant de Vicent (el que escriu l'autor) i el cant a València (el que ha d'escriure el tu protagonista, el qual també serà cant de Vicent). Hi veiem com, a nivell de contingut, es tracta l'escriptura del poema dins l'escriptura d'un poema.

El text d'Estellés és en certa manera no sols autobiogràfic sinó metapoètic. Entre els vv. 2-13 es reflexiona sobre el tipus d'escriptura: es busca aquella basada en la senzillesa («sense solemnita») i la humilitat («de manera humil»); el cant intentat creix («el miraves créixer com un crepuscle», estableix la comparació del vers novè), quan arriba el moment d'escriure, al capvespre. I a la nit s'atura, amb dubtes sobre l'escriptura. Llavors, com un parèntesi i per primera vegada, irromp la veu en estil directe de Vicent (vv. 11-13) per dir, com a jo en primera persona, que ajorna el cant a València potser fins a la mort o la «Resurrecció» (esment que també apareixia al poema lul-lià, però referint-se a Jesucrist).

A partir del v. 14 retorna l'obsessió del tema de València com si fos quelcom que assetja el $t u$ protagonista per tal de ser escrit: s'hi va del tempteig de les síl-labes fins a la realitat de cada dia, perquè «tota la teua vida - si no tota la vida,/ allò que tu saps de fonament en ella—/ anava per València, pels carrers de València» (vv. 17-19). De fet, el cant a València ja es concreta plenament entre els vv. 26-46: València són els carrers, però amb les vivències: la parella, la lleteria, la casa estrenada, el veïnat, el metge, el naixement d'un fill, el menjador, el que es veu des de la finestra, el so del port, els carros de l'hor- 
ta, l'escola, l'església... Es defensa i s'escriu tot un conjunt d'esments que testimonien detalls i instants aparentment insignificants però que condensen una vida, els quals perviuen plenament en la memòria de Vicent. Com Fèlix, el protagonista de Llibre de meravelles lul-lià, Vicent descobria la quotidianitat del món que trepitjava.

Els quatre alexandrins vv. 47-50 incorporen, des de l'exclamació «Ah, València, València!», un nou el canvi de referents en els díctics personals: ara irromp, sense marca tipogràfica, la veu directa d'un jo que és Vicent i que parla a la seua ciutat, convertida en el seu $t u$ interlocutor.

Això no obstant, el tres versos finals (vv. 51-53) recuperen el tu protagonista anterior, reprenen l'inici del poema amb el fet que Vicent encara ha d'escriure el cant a València, amb el consell per part de la veu enunciativa d'ajornar-lo (consell contrari al de l'inici del text).

De fet, anys més tard, el 1978 l'autor incloïa dins el volum Balanç de mar. Obra completa 4, un nou «Cant de Vicent», escrit entre 1970 i 1972, aquest dividit en dos textos escrits en apariats de tetrasíl-labs. Tanmateix, el seu cant ja havia estat escrit a la fi dels cinquanta, com hem vist, i era un cant sense solemnitat i amb humilitat a València, mitjançant l'esment dels detalls i els instants importants en la seua vida i que romanien intactes en la memòria; aquells que, per quotidians, solien passar desapercebuts i sobre els quals calia posar la mirada per adonar-se que eren importants o imprescindibles. És així com es troben o es perceben les meravelles. Per això l'obra, a què pertany aquest text, és un Llibre de meravelles.

Per a Llull fer poesia era aconseguir una composició basada en la versificació, amb mètrica i rima rigorosa, les quals aportaven la repetició d'estructura sil-làbica i repetició fònica, i fins i tot la recurrència de sintagmes i períodes sintàctics. Aquest tipus de configuració presentava uns continguts formatius i morals, amb intenció pedagògica i evangelitzadora. Estellés, en canvi, sense abandonar la mètrica, mostra tant la importància de la quotidianitat dels referents incorporats com el registre lingüístic emprat per redactar els versos.

Com Llull, Estellés fa un selecció de moments o dades de la seua vida i els incorpora en el seu cant. El mallorquí tenia una tasca missional, evangelitzadora; i el valencià en té de metapoètica, fer el testimoni de la quotidianitat. Tots dos busquen el cant per expressar-se: en els dos poemes hi ha un naixement («són creat» o parit a Burjassot) i una mort (Judici Final o Resurrecció de la Carn), en tots dos hi ha al-lusions a una ars nova (doctrinal o poètica), en els dos hi ha indrets (Miramar o València), en tots dos hi ha tasca que cal realitzar (conversió i evangelització o assolir el cant adequat), en els dos hi ha un ajornament no resolt (aconseguir «companyons» per continuar la conversió o aconseguir que el cant mostre veritablement València), en tots dos hi ha una queixa de l'entorn (el «fals senyor» i aquells que «meten el món en error» o el que perd els «indígenes») i en els dos hi ha un poema que és un cant personal (de Ramon o de Vicent). El poeta valencià pren del mestre mallorquí del segle XIII la idea de fer un cant i el transforma 
seriosament (Genette 1982): la transposició trasllada a la València del segle xx. Frustració i crisi hi havia en l'actitud de Llull en tornar de París i no aconseguir salvar Miramar. Estellés apunta el fracàs del cant, que diu ajornar, per presentar-nos-el, mostrar-nos la seua poètica i assenyalar-nos el que entén per meravelles.

Set segles els separaven en el temps. Es pot afirmar que Llibre de meravelles ret homenatge a Ramon Llull (a més d'Ausiàs March), és a dir, al creador de la llengua literària. Cal recordar que la primera intitulació dels originals de l'obra estellesiana era Oda a l'aparició de la gramàtica. Li ret homenatge pel títol definitiu, per la citació de Batllori, per l'estructura del llibre, pel medievalisme de l'obra i pel poema «Cant de Vicent». Anys més tard el mateix autor incloïa dins «Llibre dels poetes», al tercer volum de Mural del País Valencià (1996), escrit durant la segona part dels anys setanta, un poema intitulat «Ramon Llull» (tot i ser la magna obra estellesiana un mural sobre el País Valencià), el qual reproduïm per acabar:

\section{RAMON LLULL}

M'he submergit dintre el teu món atarantat per focs, per besllums, llistant el món acabat de nàixer, com acabat de fer semblava tot: el jorn, els beneïts aladres, els aljubs salpassats, les alzines, els merlets esdentats.

Semblant un bosc caminava el poble vers el destí de vaixells, gavines.

Tot era clar entre la gran multiplicitat d'arrels.

Sabem qui és el traïdor.

Entrant al port es belluga el dia.

Cremen els focs.

Ah del castell, han contestat des de les tombes.

Cauen estels.

Fundació! 


\section{BIBLIOGRAFIA}

Andrés Estellés, V. (1971) Llibre de meravelles, València, L’Estel.

Andrés Estellés, V. (1996) Mural del País Valencià, València, Edicions Tres i Quatre.

Andrés Estellés, V. (2013) Animal de records (Memòries), Alzira, Bromera.

Andrés Estellés, V. (2015) Obra completa II, València, Edicions Tres i Quatre.

Aparicio, M. (2003) «Les fonts clàssiques de Vicent Andrés Estellés», L’Aiguadolç. Revista de literatura, 28/29, monogràfic «Homenatge a Vicent Andrés Estellés», pp. 23-58.

Aparicio, M. (2013) «Vicent Andrés Estellés i els clàssics catalans», dins Salvador, V. + Pérez-Saldanya, M. (eds.) L'obra literària de Vicent Andrés Estellés, València, Acadèmia Valenciana de la Llengua, pp. 93-122.

Batllori, M. (1993) Ramon Llull i el lul.lisme, València, Edicions Tres i Quatre.

Calvo, A. (2007) Le referentiel et l'intertextualité dans l'oeuvre poétique de Vicent Andrés Estellés, Paris, Université de Paris 8, tesi doctoral.

Carbó, F. (2009) Com un vers mai no escrit. La poesia de Vicent Andrés Estellés en els anys cinquanta, Barcelona- València, Publicacions de l'Abadia de Montserrat- Institut Interuniversitari de Filologia Valenciana.

Carbó, F. (2014) «La poesia de Vicent Andrés Estellés entre el 1952 i el 1958: de les homilies a les tenebres», estudi introductori dins Andrés Estellés, V. Obra completa I, València, Edicions Tres i Quatre, pp. 11-63.

Carbó, F. (2015) «La poesia de Vicent Andrés Estellés entre la fi dels anys cinquanta i l'inici dels seixanta: de les tenebres a les meravelles», estudi introductori dins Andrés Estellés, V. Obra completa II, València, Edicions Tres i Quatre, pp. 9-54.

Carbó, F. + Gregori, C. + Lluch, G. + Rosselló, R. + Simbor, V. (2008) El bricolatge literari. De la paròdia al pastitx en la literatura catalana contemporània, Barcelona, Publicacions de l'Abadia de Montserrat.

Fuster, J. (1972) «Nota — provisional i improvisada - a la poesia de Vicent Andrés Estellés», dins Andrés Estellés, V. Obra completa 1. Recomane tenebres, València, Eliseu Climent editor, pp. 17-36.

Genette, G. (1982) Palimpsestes. La littératures au second degré, París, Seuil.

Genette, G. (1987) Seuils, París, Seuil.

Keown, D. (2000) Polifonia de la subversió. La veu col-lectiva de Vicent Andrés Estellés, València, Tàndem.

Llull, R. (1957-1960) Obres essencials, Barcelona, Selecta, Biblioteca Perenne, 2 vols. a cura de M. Batllori, J. Carreras, J. Rubió, A. Sancho, M. Arbora, L. Riber, A. Badia, F. De B. Moll, J. Romeu, R. Guilleumas. 
Llull, R. (1958) Poesies, Barcelona, Selecta, Biblioteca Selecta. A cura de Romeu, J.

Piégay-Gros, N. (1996) Introdution à l'intertextualité, Paris, Dunod.

Oviedo, J. (2017) «La poesia estellesiana entre els anys 60 i els primers 70: silenci editorial, identitat i ficcionalització literàries», estudi introductori dins Andrés Estellés, V. Obra completa IV, València, Edicions Tres i Quatre, pp. 7-66.

Pérez Montaner, J. (2009) El mural com a fons. La poesia de Vicent Andrés Estellés, Catarroja, Perifèric edicions.

Reduccions (2011) 98/99, abril, monogràfic «Vicent Andrés Estellés».

Riquer, M. de (1980) «Ramon Llull», dins Riquer, M. de + Comas, A. + Molas, J. Història de la literatura catalana, I, Barcelona, Ariel, pp. 197-352. Segona edició.

Romeu, J. (1983) «Interpretació del "Cant de Ramon" de Llull», Serta Philologica F. Lázaro Carreter, II, Madrid, Càtedra, pp. 449-463. Inclòs dins Garolera, N. (ed.) (1985) Anàlisis i comentaris de textos literaris catalans, 3, Barcelona, Curial, pp. 9-34.

Salvador, V. (2016) «Els primers anys seixanta i el silenci editorial: de les meravelles als esbossos de relat», dins Andrés Estellés, V. Obra completa III, València, Edicions Tres i Quatre, pp. 7-49.

Salvador, V. + Pérez-Saldanya, M. (eds.) (2013) L'obra literària de Vicent Andrés Estellés, València, Acadèmia Valenciana de la Llengua.

Sanchis Guarner, Manuel (1971) «Pròleg», dins Andrés Estellés, V. Llibre de meravelles, València, L'Estel, pp. 7-10. 
